\title{
Características de las Empresas Sociales Periodísticas
}

\author{
Francisco Javier Caro-González \\ Macarena Pérez-Suárez \\ Isadora Sánchez-Torné
}

RESUMEN: El sector de las empresas de comunicación está experimentando importantes cambios motivados por la irrupción de la tecnología digital y la pérdida de credibilidad de los medios informativos tradicionales. En esta situación están emergiendo nuevos modelos de negocios sostenibles, entre ellos las Empresas Sociales. En la literatura no se ha abordado con detalle la definición del concepto de Empresa Social Periodística (ESP), ni de las características que las determinan. El marco teórico de esta investigación ha sido la conceptualización dada por EMES (European Research Network), que identifica 11 criterios para reconocer a las Empresas Sociales, unos principios que se agrupan en tres dimensiones: económica y emprendedora, social y gobernanza participativa. El objetivo general es identificar las características de las ESP, determinar las variables asociadas al "no lucro» y examinar el encaje con el enfoque de la Empresa Social propuesto por EMES. Para conocer las diferencias entre las empresas periodísticas emergentes que se autodenominan "con ánimo de lucro" y "sin ánimo de lucro", se realizó un análisis exploratorio e inferencial de los emprendimientos periodísticos recogidos en el directorio de empresas SembraMedia (509 medios). Se tuvieron en cuenta variables clave como: fundadores, misión, género periodístico, propietarios, fuentes de ingresos y fuentes informativas. Las aportaciones principales de este trabajo son dos. En primer lugar, abordar un sector que no es contemplado habitualmente en los estudios de la Empresa Social, enriqueciendo el campo de estudio. En segundo lugar, contribuir a la conceptualización de la Empresa Social Periodística en el marco del enfoque EMES.

PALABRAS CLAVE: Empresas Sociales, Empresa periodística, Empresas sin ánimo de lucro, Periodismo, Economía Social.

CLAVES ECONLIT: A13, O35, L82, D64.

Cómo citar este artículo / How to cite this article: CARO-GONZÁLEZ, F.J., PÉREZ-SUÁREZ, M. \& SÁNCHEZTORNÉ, I. (2019): "Características de las Empresas Sociales Periodísticas", CIRIEC-España, Revista de Economía Pública, Social y Cooperativa, 96, 121-154. DOI: 10.7203/CIRIEC-E.96.12723.

Correspondencia: Francisco Javier Caro-González, Departamento de Administración de Empresas y Marketing, Universidad de Sevilla, fjcaro@us.es; Macarena Pérez-Suárez, Departamento de Economía Aplicada III, Universidad de Sevilla, mperez32@us.es, e Isadora Sánchez-Torné, Departamento de Economía Aplicada III, Universidad de Sevilla, isanchez6@us.es. 


\section{EXPANDED ABSTRACT}

\section{Characteristics of the Social Journalistic Enterprises}

\section{Contextualization}

The sector of communication companies is undergoing important changes, some of which are motivated by the eruption of digital technologies and the loss of credibility of traditional media. This situation is favoring the emergence of new forms of journalism and new sustainable business models (Galan, 2017); many of these models are cataloged as Social Enterprises. However, the Social Enterprise concept is not sufficiently developed in the field of communication.

Only in Spain, during the economic crisis (2008-2016), journalists have created more than 500 media that try to face the employment precariousness and the lack of credibility of the sector (Palacios, 2015). The new business models appear as one of the solutions to guarantee the survival of the journalistic company (Larrañaga-Rubio, 2010). These emerging forms are oriented, on the one hand, to create quality of employment, and on the other hand, to meet the need for information from society through innovations in services or information products. These journalistic projects adopt legal forms very different from each other; some forms can be cataloged as Social Enterprises. A simple look at their websites shows how they fit the definition provided by the European Commission: they are organizations "whose main objective is to have a social impact beyond the generation of a benefit for their owners or shareholders. They work providing goods and services to the market through entrepreneurship and innovation, as well as using its benefits primarily to achieve social objectives. They are managed in an open and responsible manner and, in particular, involve workers, consumers and interest groups affected by their commercial activity" (COM-2011, 682:2, Brussels, 25.10.2011). Notwithstanding, there is no definition of the term Social Journalistic Enterprise (SJE), nor of the characteristics that can help to identify this sort of organization. In general, Social Enterprise is a concept that is not yet delimited theoretically and about which there is some confusion due to the existence of different approaches (Cabra de Luna, 2017). In addition, providing this definition is even more complicated if it is limited to the specific field of journalism.

\section{Objective}

The main objective of this work is to identify the characteristics of the SJE in order to determine the variables associated with "non-profit" organization and to examine the fit to the approach of Social Enterprise proposed by EMES (European Research Network) (Defourny and Nyssens, 2012). 


\section{Methodology}

To achieve the objective, the digital media collected in the SembraMedia Directory are analyzed. In this database, the information has been obtained from 509 companies: 365 self-described as "nonprofit" and 144 as "for profit". This provides information of several variables: the founding members, the mission, the type of journalistic genre, the owners, the sources of income and the informative sources, among others. In each group, the common elements from the different variables have been researched. Subsequently, the results of each group have been compared. The data are analyzed statistically through SPSS software. On the other hand, the theoretical focus of reference for the development of this research is the conceptualization offered by EMES, who identifies 11 criteria grouped into three dimensions: 1 economic and entrepreneurial; 2) social; and 3) participative management. Among the 11 criteria, there is agreement in the scientific community on the non-distribution of benefits as the most determinant criterion. "The criterion of non-profit constitutes a guarantee for consumers (...) The absence of profit is a protection against two negative phenomena: adverse selection and moral risk" (Laville, 2015: 94). For this reason, this criterion will serve to select the companies of the journalistic sector beforehand. In view of the variables included in the directory, the EMES criteria for the Social Enterprise and the nature of the information activity, seven hypotheses have been established.

\section{Results}

The outcomes are presented from seven differentiating variables between for-profit organizations (CAL) and non-profit organizations (SAL). From this, the main findings are that $71.71 \%$ are for-profit organizations (CAL) and $28.29 \%$ non-profit (SAL). Most of the companies are based in Latin America. Significant differences are found between the CAL and SAL companies, mostly related to the business model as digital media. An example of this is how SAL organizations show a significantly greater result in "foundations and subsidies", "education" and "entertainment and workshops". The territorial coverage in the group of companies analyzed is fundamentally national (78.55\% CAL and $73.38 \% \mathrm{SAL}$ ). Only in the international contents were significant differences found between both media, being the CAL media those that presented the highest percentage. In general, the main subjects of the digital media studied are three: culture and entertainment (55.07\% CAL and 54.17\% SAL), politics (48.88\% CAL and $43.26 \% \mathrm{SAL}$ ), and society and human rights (42.13\% CAL and $51.77 \% \mathrm{SAL})$. Regardless of these results, the SAL media showed a significantly higher result in the environmental issue. In relation to the journalistic genre used by digital media, the most used was the "informative" $(62.35 \% \mathrm{CAL}$ and $44.86 \% \mathrm{SAL}$ ). On the other hand, significant differences have been found with higher percentages in the SAL organizations in four genres. The most recurrent technique used to compile the information is "news or breaking news". At the same time, it was the CAL organizations that opted more for this modality, while the SAL entities showed a significantly greater result in "coverage and data journalism". All the digital media work with professional journalists to elaborate the content of their news, although it is the CAL organizations that work with them in a significantly higher percentage. On the other hand, 
$15.83 \%$ of SAL organizations use content prepared by the founders, while the CALs only use $5.36 \%$. All these results let us identify the characteristics associated with non-profit organizations and interpret them, based on the definition of Social Enterprise suggested by EMES.

\section{Practical conclusions and original value. Implications and limitations to research}

There are important differences between digital media with and without profit motive in terms of: financing, thematic content and its origin, scope of news, support platform used, journalistic technique and gender used. These differences allowed us to develop the seven hypotheses. The main contributions of this work are two: we address a sector that is not usually studied in the field of the Social Enterprise, thus contributing to this field and to the conceptualization of the Social Journalistic Company within the framework of the EMES approach. In any case, the authors of this research agree with Nogales (2017:122) that "the most important aspects of the Social Enterprise are not the precise contours of its definition, but a common shared notion that captures its added value is necessary, mostly at the time of initiating public policies and actions both citizens and in the business sector that promote their development". The importance of this research lies in generating new empirical evidence on two topics, Communication Sector and Social Enterprise, in a relation in which the literature has significant deficiencies. Regarding the limitations of this research, we can identify two: the sample, since a greater number of companies may be useful to qualify and observe more variables; and the empirical limitation, derived from the limitation in time and the data capture method of capturing data.

KEYWORDS: Social Enterprises, Journalistic Enterprise, Non-profit organization, Journalism, Social Economy. 


\section{Introducción}

Los cambios en el sector de la comunicación y en la sociedad demandan respuestas innovadoras por parte de los profesionales de la información. El ecosistema tradicional de medios basados en la propiedad privada o pública de las empresas de comunicación se muestra insuficiente en una sociedad compleja, solidaria, digitalizada e interactiva. En este contexto, la información periodística debe ser considerada un bien de primera necesidad al servicio de la ciudadanía, tal vez, un bien comunal (Ostrom,1990). Numerosas empresas del sector tienen vocación de servicio y su labor trasciende más allá de la mera obtención de beneficios.

En esta realidad, surge la necesidad de conocer cuál es la vinculación entre los modelos organizativos emergentes del sector de la comunicación con la Economía Social (ES) y de qué manera dan respuesta a los retos sociales del siglo XXI. Desde sus inicios, la labor periodística ha estado muy próxima a los fundamentos de la Economía Social, así, Nieto e Iglesias (1993) apuntan que la principal finalidad de estas empresas es favorecer los derechos y deberes de las personas y lograr el fin común. La empresa periodística es catalizadora del cambio ya que cubre importantes necesidades sociales sin que sus directrices fundamentales sean, a priori, la obtención de rentabilidad. Caro-González (2007) señala que hasta bien entrado el siglo XXI los manuales de empresa periodística no mencionan el beneficio económico en su conceptualización, a pesar de ser el rasgo distintivo de las definiciones aportadas por la Economía de la Empresa en las que se basan diferentes autores (Nieto e Iglesias, 1993, 2000; Población y García-Alonso,1997). El beneficio económico era un medio para ofertar un servicio público.

Con la crisis económica iniciada en $2008^{1}$ y la hegemonía de lo digital en la comunicación, las empresas del sector se reinventan y buscan nuevas fórmulas que les permitan satisfacer las necesidades informativas de la ciudadanía. Es donde surgen modelos organizativos innovadores (El Salto², $\mathrm{SBP}^{3}$, La Marea 4 , etc.). Mientras que, a nivel conceptual se constata que no hay una definición de Empresa Social Periodística (ESP). Las distinciones esenciales hacen referencia a empresas con o sin ánimo de lucro, sin detenerse en buscar otras características adicionales que puedan enmarcarse en la amplia literatura desarrollada por los académicos de la Economía Social. Por tanto, el objetivo general de esta investigación es identificar las características de las ESP, determinar las variables asociadas al «no lucro» y examinar el encaje con el enfoque de la Empresa Social propuesto por EMES. En otras palabras, se quiere contribuir a la caracterización de la Empresa Social en general y de la

1.- Fuente: https://europa.eu/european-union/topics/economic-monetary-affairs_es (Consultado 01.06.2018).

2.- Fuente: https://www.elsaltodiario.com (Consultado 01.04.2019).

3.- Fuente: http://sebuscanperiodistas.com (Consultado 01.04.2019).

4.- Fuente: https://www.lamarea.com (Consultado 01.04.2019). 
ESP en particular. De esta forma se amplía el campo de estudio y se dota de mayor visibilidad a este tipo de empresas.

La relevancia de este trabajo reside en proponer una definición de Empresa Social Periodística (ESP) y poner en valor este sector en la Economía Social.

A pesar del impacto que las ESP tienen en el bienestar social, como explicaremos más adelante, actualmente no es objeto de atención entre los académicos. Evidentemente, de forma más general si se ha abordado la evolución de las organizaciones no lucrativas hacia la Empresa Social (Salinas y Rubio, 2001; Argudo, 2011), pero no es el caso de la empresa periodística. Del mismo modo, se aspira a consolidar la Empresa Social como un área estructurada de investigación en comunicación, con un enfoque multidisciplinar que permita identificar y categorizar casos de éxito empresariales.

\section{Revisión de la literatura}

\subsection{La información como bien común al servicio de la sociedad del bienestar}

Las organizaciones de la Economía Social cubren las necesidades básicas que el sistema capitalista deja en la sociedad y/o los efectos no deseados que se derivan de esta ideología (Monzón, 2003) y que impide una satisfacción eficiente y solidaria de las necesidades de la ciudadanía (Navarro, López y Espinosa, 2011). Las empresas y emprendimientos sociales (Enciso, Gómez y Mugarra, 2012), y consecuentemente, la innovación que conllevan, sirven como elemento corrector de los intereses particulares, regidos fundamentalmente por los principios de oferta y demanda, y de rentabilidad económica.

En este punto cabe reflexionar sobre lo que se considera una necesidad social (Defourny y Nyssens, 2012), pues tradicionalmente, el bienestar social aparece ligado a actividades como salud, educación y servicios a las personas, así como la cultura y acceso a las necesidades básicas, como la vivienda o la energía (Nogales, 2017). Derivado de los cambios en el sistema económico de los últimos años, están surgiendo nuevas necesidades, las cuales no están siendo satisfechas en su totalidad (Barrera, 2007).

El desarrollo de la sociedad de la información y el conocimiento está provocando enormes desigualdades entre los que tienen acceso a la información y los que no (Delarbre, 2001); entre los que pueden hacerse oír y aquellos cuya voz permanece silenciada por el sistema mediático mediante el establecimiento de una agenda excesivamente politizada e institucionalizada. Bajo esta trama, la infor- 
mación es un bien de primera necesidad que incrementa el bienestar de la ciudadanía, la igualdad y la cohesión social, al mismo tiempo que fortalece el sistema democrático. La calidad democrática de un país está asociada a la calidad de la información con la que cuentan las personas electoras.

Una ciudadanía informada puede elegir mejor a sus representantes y tener una visión crítica respecto a las estructuras de poder. La información en general, y la información periodística en particular, son fundamentales para la estabilidad democrática y la participación ciudadana. Al mismo tiempo, un sistema de información más plural y accesible contribuye a reducir la asimetría informativa que existe en la sociedad, permitiendo que individuos de diferentes estratos sociales obtengan un recurso esencial para alcanzar la igualdad, el reconocimiento y el acceso a las oportunidades. La información no debe ser tratada como una mercancía, sino como un derecho fundamental de la ciudadanía. Hay autorías que incluso plantean que el periodismo tal y como ha sido concebido no tendría razón de ser si no tiene un propósito social (Siapera y Papadopoulou, 2016).

En 1993 el Consejo de Europa aprobó los principios que deben regir en el ejercicio del periodismo involucrando a personas periodistas, editoras y empresarias: "los medios de comunicación efectúan una labor de mediación y prestación del servicio de la información y los derechos que poseen en relación con la libertad de información están en función de los destinatarios que son los ciudadanos" (BonetePerales, 1995:265). Sin embargo, como señala Kapuscinski (2007), la noticia se ha convertido en un negocio y un espectáculo para ganar dinero rápidamente. Squires (1994:183) ya anotaba que no es realista pensar que los directivos profesionales de los medios vayan a aceptar alguna vez beneficios menores a cambio de un periodismo mejor y más tradicional. Las reducciones salariales y la dependencia financiera de los grandes grupos mediáticos están provocando la pérdida de la autonomía profesional y económica, afectando directamente a la independencia informativa y a la credibilidad de la profesión periodística (Aguado, Gil-Jaurena y Mata-Benito, 2008; Galán, 2017). Del mismo modo, la manipulación que los gobiernos hacen de los medios públicos provoca la desconfianza de la ciudadanía.

Por lo tanto, se puede considerar que no existe la garantía de pluralidad informativa. Si se quiere mantener el estado del bienestar en términos informativos hay que dar paso a un tercer actor y compartir esta responsabilidad entre el Estado, la empresa privada y la iniciativa social. Las empresas periodísticas emergentes pueden contribuir a lo que la Comisión Europea ha denominado Innovación Social entendida como "nuevas formas de satisfacer las necesidades sociales que no están adecuadamente cubiertas por el mercado o el sector público (la información como hemos explicado) (...) o en producir los cambios de comportamiento necesario para resolver los grandes retos de la sociedad (inclusividad, cohesión, sostenibilidad)"5.

Esta investigación tiene una indudable utilidad social al contribuir a visibilizar y potenciar las Empresas Sociales como complemento a los sistemas de medios tradicionales, fomentando un proceso colectivo para el progreso de la vida cotidiana a partir de la información. Los contenidos infor-

5.- Fuente: http://europa.eu/youth/es/article/59/49200_es (Consultado 01.06.2018). 
mativos se plantean en términos de servicio a la sociedad que ayude a la ciudadanía a resolver problemas: "con demasiada frecuencia, los periodistas encuentran un problema, informan sobre él o se quejan y ya está (...)" (Jarvis, 2015: 73).

Se trata de un fenómeno detectado en Estados Unidos, donde la sociedad civil se está fortaleciendo gracias a la aparición de nuevos medios de comunicación orientados a servir a su comunidad, más allá de la búsqueda del valor económico (Knight, 2015). El público sigue cada vez más estos nuevos medios y abandona a los tradicionales al considerarlos más creíbles (Cross, 2017). Tendencia que favorece a los medios de comunicación sin fines de lucro y a sus signos de salud económica (Mitchell, Jurkowitz, Holcomb, Enda, y Anderson, 2013). A continuación, con brevedad, se alude a la definición y contextualización de la Empresa Social en el seno de la Economía Social.

\subsection{Definición de la Empresa Social}

La Comisión Europea presentó en 2011 una comunicación que define a las Empresas Sociales como aquellas "cuyo principal objetivo es tener un impacto social más allá de la generación de un beneficio para sus propietarios o accionistas. Opera aportando bienes y servicios para el mercado a través del emprendimiento y la innovación y utiliza sus beneficios fundamentalmente para el logro de objetivos sociales. Son administradas de forma abierta y responsable y, en particular, involucran a los trabajadores, consumidores y grupos de interés afectados por su actividad comercial" (COM 2011/682; Bruselas, 25.10.2011). Díaz-Foncea, Marcuello y Marcuello (2012: 187) añaden que "en el conjunto de las organizaciones no lucrativas se percibe una mayor preocupación por demostrar sus resultados".

Según Defourny y Nyssens (2012:5), "en Europa, el concepto de Empresa Social aparece por primera vez a principios de la década de 1990, en el corazón del tercer sector". A lo que Díaz-Foncea, et al. (2012: 183) añaden que "a partir de las distintas experiencias, la literatura académica ha detectado diferentes modelos de empresas sociales que proceden de la tradición europea continental y de la tradición anglosajona". Ciertamente, se identifican el enfoque europeo (Defourny y Nyssens, 2012) y los enfoques norteamericanos ${ }^{6}$ (Monzón y Herrero-Montagud, 2016).

En particular, Díaz-Foncea y Marcuello (2014:146) mencionan que "EMES define Empresa Social como aquellas organizaciones privadas no lucrativas que proporcionan bienes y servicios directamente relacionados con su objetivo explícito de beneficio a la comunidad. Se basan en una dinámica colectiva de forma que implica a los diferentes grupos de interés en sus órganos de gobierno, son entidades autónomas y soportan los riesgos relacionados con su actividad económica". Definición ya distinguida por Argudo (2011: 180), al mostrar que las empresas sociales se caracterizan "por su fina-

6.- Por su parte, las diferentes corrientes de pensamiento norteamericanas sobre la empresa social se han agrupado en dos enfoques principales: el de "generación de ingresos" y el de la escuela de pensamiento «innovación social». (Monzón y Chaves, 2012: 26). 
lidad social, su carácter no lucrativo y su gestión de carácter empresarial". Salinas y Rubio (2001: 102) rubrican que "la acción de la Empresa Social genera cohesión social y promueve una acción basada en la solidaridad, pero al mismo tiempo se la desplaza de aquellos espacios más rentables, progresivamente capturados por las empresas lucrativas". Díaz-Foncea et al. (2012: 183) señalan que "la definición de Empresa Social requiere de una aproximación multidimensional en la que se conjugan elementos tradicionales de la empresa y de la Economía Social, que afectan especialmente al objeto social, la motivación económica y los modelos de gestión de este tipo de organizaciones". SolórzanoGarcía, Guzmán-Alfonso, Savall-Morera y Villajos-Girona (2018: 160), matizan que las empresas sociales tienen como objetivo "la generación de valor social para los beneficiarios de su misión social y su fuente de ingresos principal es la vía comercial, dependiendo del mercado para su sostenibilidad financiera, de forma que las actividades comerciales se entienden como medios para obtener sus fines".

\subsection{Las Empresas Sociales en el seno de la Economía Social}

Primeramente, según Pérez de Mendiguren, Etxezarreta y Guridi (2009:25-26) habría que reconocer que "entre estos dos campos de estudio y sus respectivas "escuelas" se perciben grandes afluencias, amplios lugares de encuentro, pero al mismo tiempo ciertas tensiones (...) se aboga también cada vez más por un concepto que supere el corsé formal, que prescinde de las formas jurídicas y que atiende en mayor medida a lo sustancial de las empresas, que es en última instancia su actividad y su objeto social".

La vinculación entre la Empresa Social y la Economía Social es reconocida. Así lo señalan DíazFoncea et al. (2012:183), "los valores y principios de la Economía Social delimitan el contexto de referencia de la definición de Empresa Social propuesta por EMES. Este enfoque, considera que la definición de Empresa Social tiene sus raíces en la tradición europea continental y que ha dado lugar a un modelo vinculado a la existencia de emprendedores colectivos que surgen como organización de los ciudadanos buscando respuestas y soluciones a sus necesidades en la provisión de bienes y servicios para la mejora del bienestar de las personas". De igual manera, Monzón y Chaves (2012: 21) afirman que "desde el punto de vista práctico, absolutamente todas las organizaciones que se consideran parte integrante de la economía solidaria también forman parte inequívoca de la Economía Social. Lo mismo puede decirse de otros desarrollos teóricos como el de tercer sector de utilidad social (Lipietz, 2001), Empresa Social (Borzaga y Defourny, 2001) (...)". Específicamente, señalan que "la Comisión Europea no solo facilitó una descripción de las características de las empresas sociales, sino que afirmó expresamente que conforman una parte integrante de la Economía Social: «Una Empresa Social, agente de la Economía Social, es una empresa cuyo principal objetivo es tener una incidencia social (..) (Comunicación de la Comisión Europea, Iniciativa en favor del emprendimiento social, COM/2011/0682 final de 25 de octubre de 2011)»" (Monzón y Chaves, 2012: 24). 


\subsection{Las Empresas Sociales adquieren importancia en la crisis del sector de la comunicación}

En particular, la situación de transformación del sector está provocando que surjan nuevas formas de hacer periodismo y se busquen nuevos modelos sostenibles de negocios (Galán, 2017). En este sentido la Organización para la Cooperación y el Desarrollo Económico (OCDE), considera que la industria de la comunicación es uno de los terrenos donde se pueden llevar a cabo innovaciones importantes, por la diversificación de la demanda y la fragmentación de su mercado (De Mateo, Bergés y Sabater, 2009).

Superados los inicios, la Empresa Social puede ayudar a transformar el mundo, se presenta como una oportunidad para derribar los muros que aíslan a diferentes colectivos y apostar por el cambio social. Por ejemplo, en España, durante la crisis (2008-2016) los periodistas han creado más de 500 nuevos medios que tratan de ofrecer respuestas a la situación de penuria económica y de credibilidad del sector (Palacios, 2015). La búsqueda de nuevos modelos de negocio parece una de las soluciones que garantizan la supervivencia de la empresa periodística (Larrañaga-Rubio, 2010). Estas formas emergentes se orientan, por un lado, a crear empleo de calidad en una profesión azotada por la crisis (el caso de SBP7), y por otro, satisfacer la necesidad de información de la sociedad mediante innovaciones en servicios o productos informativos. Unos proyectos periodísticos que adoptan diversas formas legales, muchas de ellas cercanas o de la Empresa Social.

La promoción de las Empresas Sociales en el periodismo es relevante por su capacidad de crear empleo de calidad y construir una sociedad más sostenible, integradora y democrática. Sin embargo, al igual que ocurre en el resto de disciplinas, no hay una cultura específica del emprendedor social y no existe formación específica en emprendimiento de Economía Social (Poyato, 2017). En otras palabras, de acuerdo con Melián, Campos y Sanchis (2011), "en la literatura económica no existe un reconocimiento explícito y claro del emprendimiento social y de la figura del emprendedor social".

\subsection{Delimitar las Empresas Periodísticas como Empresa Social}

No existe una definición de Empresa Social Periodística (ESP), y este es el primer reto a que se quiere atender en esta investigación. Para ello, hay que determinar el tipo de organizaciones periodísticas que encajan en la Empresa Social y, seguidamente, identificar sus características. Esta tarea es compleja por dos razones:

7.- Asociación de profesionales y empresas del sector de la comunicación de Andalucía fundada en 2012. Se Buscan PeriodistasComunicadores Asociados, es una entidad sin ánimo de lucro que busca mejorar la empleabilidad en el sector a la vez que realiza un periodismo de calidad (http://sebuscanperiodistas.com/) (Consultado 01.06.2018). 
Es un concepto que no está delimitado teóricamente de forma general y sobre el que hay cierta confusión teórica debido a la existencia de diferentes enfoques (Cabra de Luna, 2017; Nogales, 2017). Y el sector de la comunicación está experimentando una transformación radical que hace que aparezcan modelos organizativos innovadores difíciles de clasificar con los parámetros actuales.

En el momento de desarrollar el concepto de Empresa Social, se refiere la escuela europea, cuyo principal valedor es EMES. Este enfoque tiene un amplio uso dentro de la literatura académica (DíazFoncea y Marcuello, 2014). También cuenta con el reconocimiento de las instituciones, como señalan Monzón y Chaves (2012: 26-27) "el enfoque EMES conforma el concepto de Empresa Social que ha prevalecido en los documentos de las instituciones de la Unión Europea" y, "es el único que sitúa de forma inequívoca a las empresas sociales en el marco teórico y conceptual de la Economía Social (...) diferenciándose del resto de enfoques sobre todo por la dinámica colectiva del emprendimiento social y por la dimensión democrática y participativa del sistema de gobernanza, ausente 0 secundaria en los enfoques norteamericanos" (Monzón y Chaves, 2012: 26-27).

EMES establece que la Empresa Social "tipo" o "ideal" debería cumplir con ciertos criterios (Defourny y Nyssens, 2014: 42-65). Los criterios se agrupan en tres dimensiones: Económica/emprendedora, Social y de Gobernanza. Partiendo de la propuesta de EMES y adaptándola al sector de la comunicación, la Empresa Social ideal en el periodismo debería ajustarse a los siguientes requisitos:

\section{Dimensión Económica y Emprendedora}

1. Tener actividad continuada de servicios informativos.

2. Poseer un significativo nivel de riesgo económico.

3. Contar con un mínimo de trabajadores asalariados, el núcleo central generador de valor en este tipo de empresas tiene que estar constituido por periodistas profesionales.

4. Llevar a cabo una gestión innovadora que permita el equilibrio entre la función social de informar y la rentabilidad económica. El periodismo debe de ser considerado un proceso social de construcción de la realidad compartida y de mantenimiento de relaciones que están orgánicamente vinculadas con la sociedad. Conceptos como innovación abierta, juegan un papel clave en este contexto empresarial.

\section{Dimensión Social}

5. Definir una misión empresarial orientada al beneficio a la comunidad (idealmente orientada al interés general). En este caso, suministrar información que incremente el bienestar de los ciudadanos reduciendo la incertidumbre respecto a su entorno. Ayudar a las personas a tomar conciencia de su realidad y a tomar decisiones en sistemas democráticos. El sector del periodismo debe com- 
prometerse a involucrar a los ciudadanos, identificar soluciones a los problemas comunes y empoderar a los lectores (Konieczna y Robinson, 2014; Ferrucci, 2015). Tienen que conseguir proporcionar información que aumente la participación cívica y cubra informativamente a las personas y a los problemas locales (Konieczna, 2014).

6. Ser una iniciativa emprendedora de un grupo de ciudadanos u organizaciones civiles. El germen del proyecto empresarial, deben ser profesionales de la comunicación (y otros profesionales) en conexión con los diferentes grupos sociales de interés (asociaciones de vecinos, ayuntamientos, etc.). Se contemplan, por tanto, las iniciativas individuales y colectivas.

7. Realizar una distribución limitada del beneficio. El beneficio que se obtiene por la actividad empresarial debe ser en gran medida utilizado para los fines sociales de la organización, aunque no necesariamente en su totalidad. Este problema del reparto del beneficio ha generado bastante controversia entre los investigadores.

8. Ofrecer una ocupación laboral de calidad. La profesión del periodismo ha experimentado un importante retroceso en la calidad del empleo durante el periodo de crisis, la precariedad se ha normalizado en el sector. Unas condiciones de trabajo minímas son indispensables para poder realizar una buena labor informativa. Trabajo digno y profesionalizado.

\section{Gobernanza Participativa}

9. Poseer un alto grado de autonomía. Tienen que ser organizaciones independientes de otras instituciones con intereses alejados de la función social del medio.

10. Funcionar de forma participativa. El funcionamiento de la organización debe ser colaborativo, y no solo entre los miembros del proyecto, sino con cualquier otro grupo de interés: trabajadores, lectores, ciudadanos, instituciones públicas, centros educativos, movimientos asociativos y cualesquiera otras instituciones interesadas en divulgar o recibir información de calidad.

11. En la línea de lo anterior, el proceso de toma de decisiones tiene que ser descentralizado y no basado en la propiedad del capital.

Con estos condicionantes la ESP se constituye como un medio para situar en primer plano los valores de pluralidad, transparencia, diversidad y solidaridad en el terreno de la información de carácter general y política. Se trata de aportar mecanismos de equilibrio por parte de la sociedad civil frente al poder del Estado y del Mercado. La ESP debe contribuir a reducir la pobreza intelectual de la ciudadanía, proporcionando información de calidad, que ayude a tomar decisiones. Al mismo tiempo, tiene que servir de altavoz para los colectivos desfavorecidos que permanecen silenciados por estructuras informativas integradas en el poder establecido. 


\section{Metodología}

El objetivo de esta investigación es contribuir a delimitar el concepto de ESP desde un punto de vista empírico. Para ello, se toma como punto de partida la clasificación en empresas "sin ánimo de lucro" o "con ánimo de lucro" que aparece en el directorio SembraMedia8. Hay acuerdo en la literatura académica en que el criterio más determinante a nivel mundial para distinguir las empresas sociales es la no distribución del beneficio: "el criterio de no lucro constituye una garantía para los consumidores (...) La ausencia de fin lucrativo es una protección frente a dos fenómenos negativos: la selección adversa y el riesgo moral" (Laville, 2015: 94). En el sector periodístico tanto la Knight Foundation 9 como el Pew Research Center ${ }^{10}$ clasifican a los modelos periodísticos según este criterio de lucro 0 no lucro.

A falta de información primaria para aproximarnos al concepto de ESP, se parte de la distinción anterior y se utiliza el directorio de SembraMedia para, de forma exploratoria, conocer si existen diferencias en los modelos de negocio de las empresas periodísticas con ánimo de lucro (CAL) y las sin ánimo de lucro $(\mathrm{SAL})$.

A la vista de las variables recogidas en el directorio, los criterios EMES para la Empresa Social y la naturaleza de la actividad informativa, se establecen las siguientes siete hipótesis:

1. Las empresas SAL ofrecen contenidos de carácter más social y considerados «blandos ${ }^{11}$ »

2. Las empresas SAL ofrecen contenidos orientados a dar voz a los colectivos más desfavorecidos.

3. Las empresas SAL ofrecen información de reflexión más que la inmediatez.

4. La financiación de las empresas SAL no tiene como principal fuente de ingresos la comercialización de la información. Es decir, deben tener fuentes de financiación ajenas al mercado (donaciones, subvenciones, etc.).

5. Las empresas SAL se financian más que las empresas CAL a través del crowdfunding.

6. En las empresas SAL hay una mayor involucración de los fundadores que en las CAL.

7. Las empresas SAL se orientan a un periodismo de proximidad, local o nacional.

8.- SembraMedia es una organización sin fines de lucro, entre sus actividades destaca el mapeado del ecosistema de medios digitales en Latinoamérica, España y el mercado hispano de Estados Unidos, y construir una red regional (https://www.sembramedia.org/quienes-somos/).

9.- Knight Foundation es una fundación estadounidense sin fines de lucro dedicada a "apoyar ideas transformacionales que promuevan periodismo de calidad, fomenten la innovación en los medios de comunicación, involucren a las comunidades y fomenten las artes" (https://www.knightfoundation.org/programs).

10.- Fuente: Consulta Website http://www.pewresearch.org/

11. - La distinción entre noticias "blandas" o "duras" fue establecida por Hellen MacGill Hughes en1940, en su publicación News and Human Interest Story. En 1978 el concepto fue desarrollado y simplificado por Tuchman en La producción de la noticia (Caro-González, García-Gordillo y Bezunartea, 2014: 991). 
Para tipificar las empresas sociales periodísticas se realizó un análisis comparativo de los emprendimientos digitales recogidos en el directorio SembraMedia. Este directorio contabiliza 509 medios iberoamericanos (a fecha del 20 de febrero de 2018) sobre los que aporta información relevante: fundadores, género periodístico, propietarios, fuentes de ingresos, técnica periodística, cobertura, nacionalidad, temática, origen de la información.

Para la extracción de los datos objeto de estudio se desarrolló un programa en lenguaje Phyton usando la librería beautiful sopup para localizar y extraer la información necesaria de la web de SembraMedia, que posteriormente se exportó a Excel e IBM SPSS (24v).

Se realizó un estudio descriptivo e inferencial (contrastes de hipótesis) para conocer si existen diferencias significativas entre las organizaciones CAL y SAL con un nivel de significación del 5\% (plevel $<0,05)$. Siendo necesario señalar que los porcentajes que se recogen en las tablas se realizan teniendo en cuenta las respuestas obtenidas, es decir, en los cálculos no se computaron aquellas respuestas Ns/Nc.

En el caso de contrastar proporciones poblacionales se utilizó la prueba $Z$ para muestras independientes que permite verificar hipótesis referidas a si existen o no diferencias entre dos proporciones provenientes de muestras independientes, que son aquellas que se examinan de forma individual.

Esta prueba contrasta las siguientes hipótesis:

- $H_{0}$ (hipótesis nula) = los porcentajes de ambas poblaciones son iguales.

- $H_{1}$ (hipótesis alternativa) = los porcentajes de ambas poblaciones no son iguales.

Así pues, cuando la prueba $Z$ arroja un resultado inferior a 0,05 (p-level $<0,05)$ se rechaza la hipótesis nula. Lo que quiere decir que existen diferencias significativas entre ambas poblaciones en la variable analizada.

La decisión de emplear esta herramienta estadística versa en el propio objetivo de la investigación, ya que a través de los contrastes se puede identificar si existen diferencias estadísticamente significativas entre los medios digitales con ánimo de lucro y sin él. Esta metodología ha sido usada previamente por otros autores para hallar diferencias significativas entre grupos, como es el caso de Pérez-Suárez, Espasandín-Bustelo y Sánchez-Torné (2017). 


\section{Resultados}

A continuación, se presentan los resultados del análisis estadístico. En primer lugar, se describe la muestra y, seguidamente, se desarrollan cada una de las variables consideradas como relevantes para dar respuesta a las hipótesis establecidas.

\subsection{Descripción}

La población está compuesta por 509 medio digitales, el $71,71 \%$ son organizaciones con fines de lucro y el $28,29 \%$ sin fines de lucro. Mayoritariamente, las empresas proceden de Hispanoamérica (Tabla 1). Destacan Colombia (14,15\%), Venezuela (13,75\%) y España (12,38\%).

\section{Tabla 1. País de Origen de los medios digitales}

\begin{tabular}{|c|c|c|}
\hline País & Frecuencia & $\%$ \\
\hline Colombia & 72 & $14,15 \%$ \\
\hline Venezuela & 70 & $13,75 \%$ \\
\hline España & 63 & $12,38 \%$ \\
\hline Chile & 49 & $9,63 \%$ \\
\hline Ecuador $\ldots \ldots \ldots \ldots \ldots \ldots \ldots \ldots \ldots \ldots \ldots \ldots \ldots$ & 48 & $9,43 \%$ \\
\hline 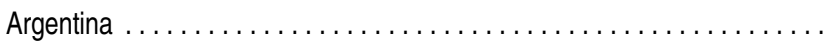 & 46 & $9,04 \%$ \\
\hline México ............. & 28 & $5,50 \%$ \\
\hline Uruguay . & 25 & $4,91 \%$ \\
\hline Puerto Rico ..... & 23 & $4,52 \%$ \\
\hline$\ldots \ldots \ldots \ldots \ldots \ldots \ldots \ldots \ldots \ldots \ldots \ldots \ldots \ldots \ldots$ & 17 & $3,34 \%$ \\
\hline Guatemala $\ldots \ldots \ldots \ldots \ldots \ldots \ldots \ldots \ldots \ldots \ldots \ldots \ldots$ & 11 & $2,16 \%$ \\
\hline El Salvador $\ldots . \ldots \ldots \ldots \ldots$. & 9 & $1,77 \%$ \\
\hline 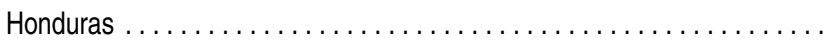 & 9 & $1,77 \%$ \\
\hline Nicaragua $\ldots \ldots \ldots \ldots \ldots$. & 9 & $1,77 \%$ \\
\hline Perú ...... & 9 & $1,77 \%$ \\
\hline Panamá & 8 & $1,57 \%$ \\
\hline 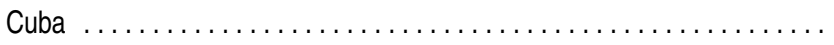 & 7 & $1,38 \%$ \\
\hline Paraguay $\ldots \ldots \ldots \ldots \ldots \ldots \ldots \ldots \ldots \ldots \ldots \ldots \ldots$ & 3 & $0,59 \%$ \\
\hline 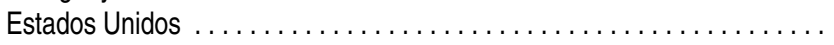 & 2 & $0,39 \%$ \\
\hline 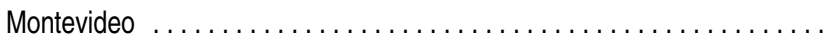 & 1 & $0,20 \%$ \\
\hline Total . & 509 & $100,00 \%$ \\
\hline
\end{tabular}

FUENTE: SembraMedia, Elaboración propia. 
Tabla 2. Fuente de ingresos de los medios digitales CAL y SAL.

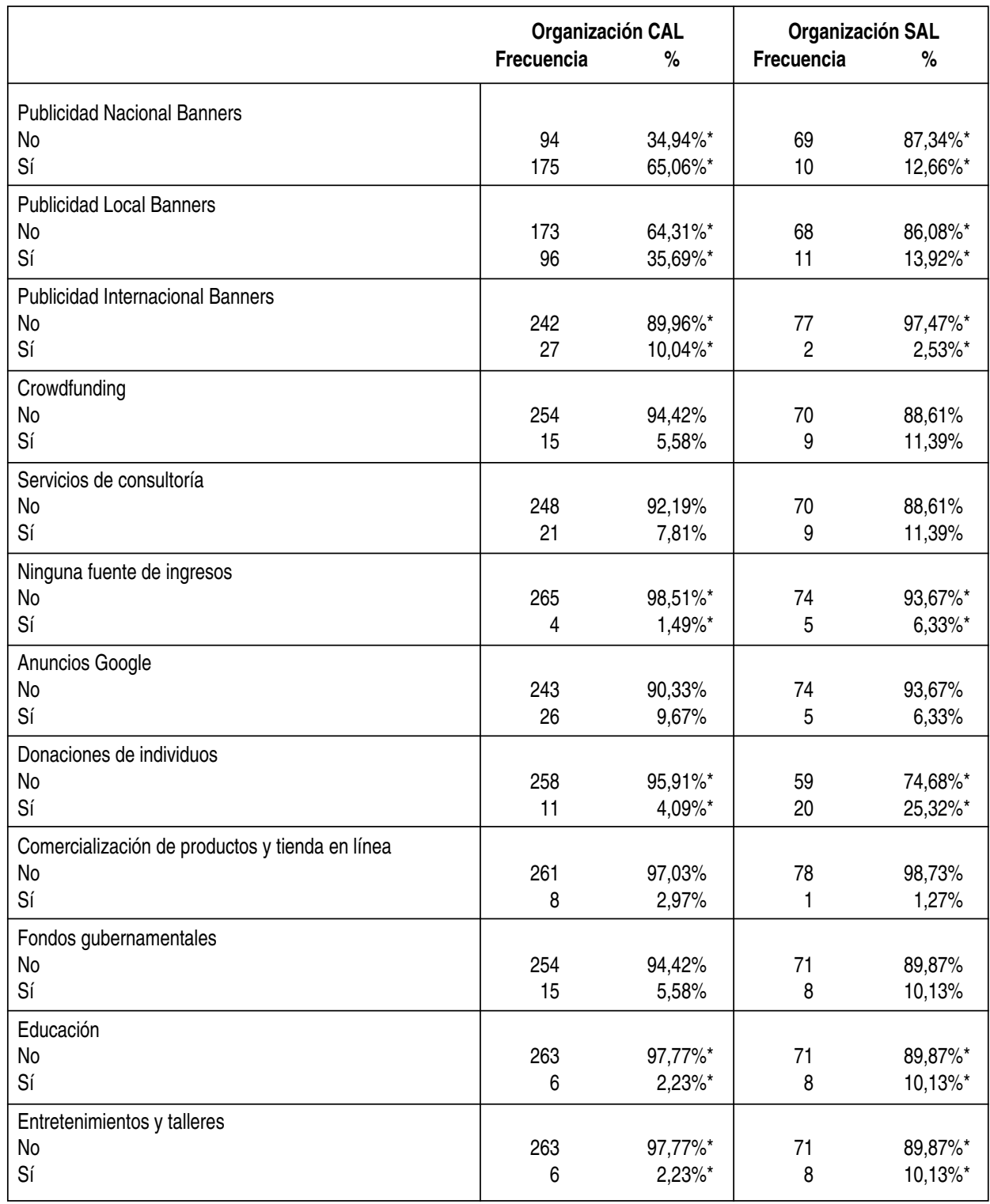




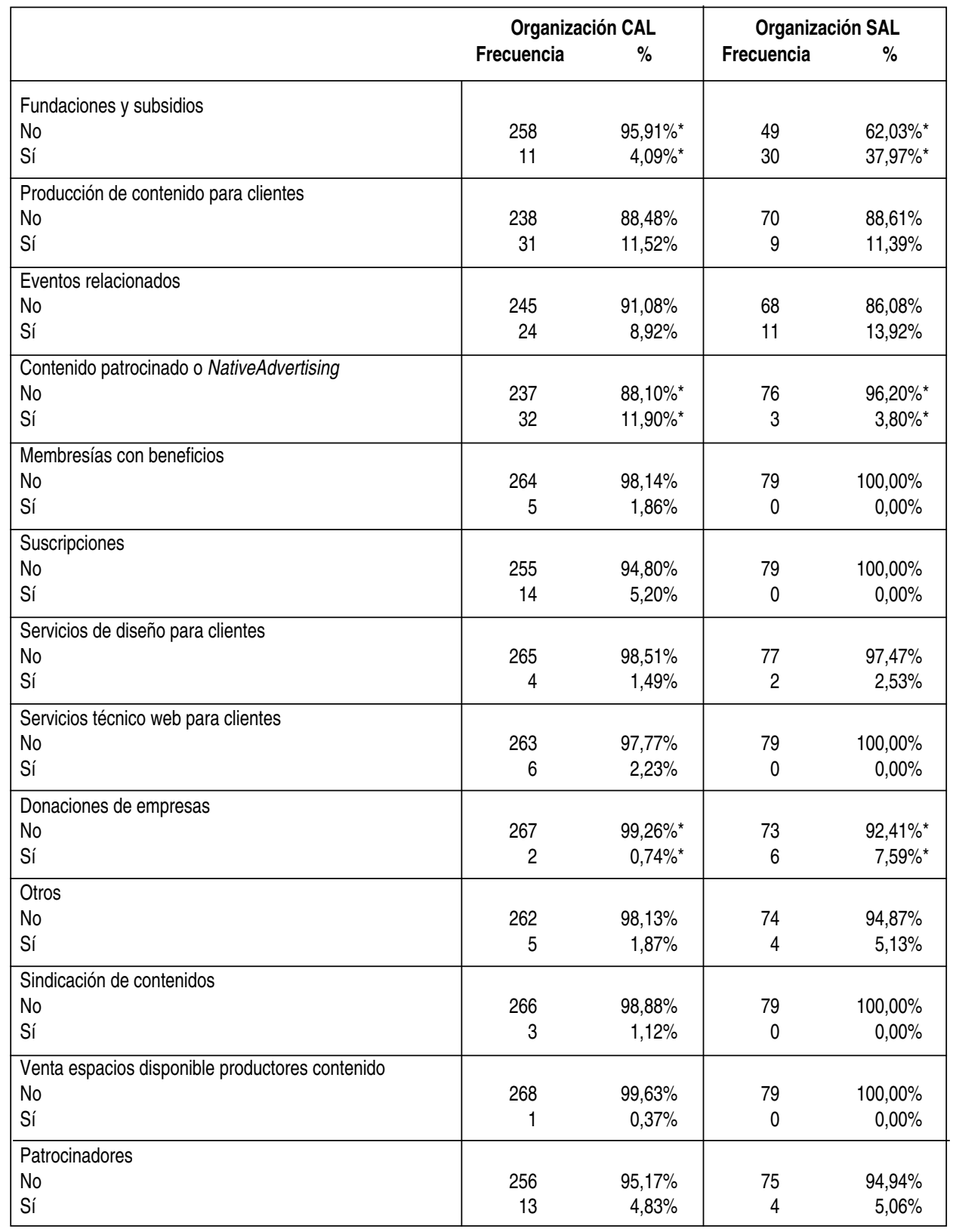

${ }^{*}$ p-level $<0,05$

FUENTE: SembraMedia. Elaboración propia. 


\subsection{Fuentes de ingresos}

La primera variable analizada hace referencia al modelo de negocio de los medios digitales. Se comprueba que existen diferencias significativas entre las empresas CAL y SAL (Tabla 2). Las primeras han evidenciado un porcentaje más elevado de ingresos en la publicidad en el formato de banners 0 de contenidos patrocinados. Las organizaciones SAL, en cambio, muestran un resultado significativamente superior en: "ninguna fuente de ingresos», "donaciones de individuos», "donaciones de empresas", "fundaciones y subsidios», "educación», «entretenimientos y talleres».

\subsection{Cobertura}

La cobertura territorial predominante (Tabla 3) en el conjunto de las empresas analizadas es nacional $(78,55 \%$ CAL y $73,38 \%$ SAL). Solo en los temas internacionales se hallaron diferencias significativas entre ambos medios, siendo aquellos medios CAL las que presentaron mayor porcentaje.

\section{Tabla 3. Cobertura de los medios digitales CAL y SAL}

\begin{tabular}{|l|c|c|c|c|}
\hline \multicolumn{2}{|c|}{\begin{tabular}{c} 
Organización CAL \\
\multicolumn{2}{|c|}{ Frecuencia }
\end{tabular}} & \multicolumn{2}{c|}{ Organización SAL } \\
\hline Internacional & & & 97 & \\
No & 201 & $58,26 \%^{*}$ & 42 & $69,78 \%^{*}$ \\
Sí & 144 & $41,74 \%^{*}$ & & $30,22 \%^{*}$ \\
\hline Nacional & & & 37 & \\
No & 74 & $21,45 \%$ & 102 & $26,62 \%$ \\
Sí & 271 & $78,55 \%$ & & $73,38 \%$ \\
\hline Local & & & 84 & \\
No & 218 & $63,19 \%$ & 55 & $39,57 \%$ \\
Sí & 127 & $36,81 \%$ & & \\
\hline
\end{tabular}

${ }^{*}$ p-level<0,05.

FUENTE: SembraMedia. Elaboración propia. 


\subsection{Tipo de contenido}

El tipo de contenido (Tabla 4) aporta información relevante para entender la dimensión social de las ESP. En general, los contenidos principales de los medios digitales estudiados son tres: cultura y entretenimiento (55,07\% CAL y 54,17\% SAL), política (48,88\% CAL y 43,26\% SAL), sociedad y derechos humanos ( $42,13 \%$ CAL y $51,77 \%$ SAL). Con independencia de estos resultados, se observa que las organizaciones CAL presentaron un porcentaje significativamente más elevado en contenidos como: tecnología, deportes, economía y negocio. En cambio, los medios SAL evidenciaron un resultado significativamente superior en la temática medioambiental.

Los contenidos sobre cultura y entretenimiento, deportes, economía y negocio, estilo de vida, judicial y político, sociedad y derechos humanos presentan subdivisiones, es decir agrupan a un conjunto de temáticas vinculadas. Por ejemplo, deporte incluye: atletismo, automovilismo, baloncesto, béisbol, tenis, futbol, deporte en general, otros. A pesar de que a nivel agregado no se hallaran diferencias, se analiza cada una de las subdivisiones, se observa que algunas presentan diferencias significativas entre ambos grupos, fue el caso de los tres últimos. Estas temáticas y sus respectivas subdivisiones se presentan a continuación.

Los contenidos principales dentro del tema "estilos de vida» fueron: eventos, viajes y gastronomía, y, concretamente las organizaciones SAL mostraron un porcentaje significativamente más elevado en la primera (Tabla 5). 
Tabla 4. Tipo de contenido de los medios digitales CAL y SAL

\begin{tabular}{|c|c|c|c|c|}
\hline \multirow{3}{*}{$\begin{array}{l} \\
\text { Ciencia } \\
\text { No } \\
\text { Sí }\end{array}$} & \multicolumn{2}{|c|}{ Organización CAL } & \multicolumn{2}{|c|}{ Organización SAL } \\
\hline & \multicolumn{2}{|c|}{ Frecuencia $\quad \%$} & \multicolumn{2}{|c|}{ Frecuencia $\quad \%$} \\
\hline & $\begin{array}{r}326 \\
30\end{array}$ & $\begin{array}{r}91,57 \% \\
8,43 \%\end{array}$ & $\begin{array}{r}136 \\
5\end{array}$ & $\begin{array}{r}96,45 \% \\
3,55 \%\end{array}$ \\
\hline $\begin{array}{l}\text { Medioambiente } \\
\text { No } \\
\text { Sí }\end{array}$ & $\begin{array}{r}299 \\
57\end{array}$ & $\begin{array}{l}83,99 \% \%^{*} \\
16,01 \%{ }^{*}\end{array}$ & $\begin{array}{r}105 \\
36\end{array}$ & $\begin{array}{l}74,47 \% \text { * } \\
25,53 \%{ }^{*}\end{array}$ \\
\hline $\begin{array}{l}\text { Periodismo } \\
\text { No } \\
\text { Sí }\end{array}$ & $\begin{array}{r}318 \\
38\end{array}$ & $\begin{array}{l}89,33 \% \\
10,67 \%\end{array}$ & $\begin{array}{r}121 \\
20\end{array}$ & $\begin{array}{l}85,82 \% \\
14,18 \%\end{array}$ \\
\hline $\begin{array}{l}\text { Política } \\
\text { No } \\
\text { Sí }\end{array}$ & $\begin{array}{l}182 \\
174\end{array}$ & $\begin{array}{l}51,12 \% \\
48,88 \%\end{array}$ & $\begin{array}{l}80 \\
61\end{array}$ & $\begin{array}{l}56,74 \% \\
43,26 \%\end{array}$ \\
\hline $\begin{array}{l}\text { Salud } \\
\text { No } \\
\text { Sí }\end{array}$ & $\begin{array}{r}286 \\
70\end{array}$ & $\begin{array}{l}80,34 \% \\
19,66 \%\end{array}$ & $\begin{array}{r}116 \\
25\end{array}$ & $\begin{array}{l}82,27 \% \\
17,73 \%\end{array}$ \\
\hline $\begin{array}{l}\text { Tecnología } \\
\text { No } \\
\text { Sí }\end{array}$ & $\begin{array}{r}261 \\
95\end{array}$ & $\begin{array}{l}73,31 \%{ }^{*} \\
26,69 \%^{*}\end{array}$ & $\begin{array}{r}118 \\
23\end{array}$ & $\begin{array}{l}83,69 \%{ }^{*} \\
16,31 \%^{*}\end{array}$ \\
\hline $\begin{array}{l}\text { Cultura y entretenimiento } \\
\text { No } \\
\text { Sí }\end{array}$ & $\begin{array}{l}164 \\
201\end{array}$ & $\begin{array}{l}44,93 \% \\
55,07 \%\end{array}$ & $\begin{array}{l}66 \\
78\end{array}$ & $\begin{array}{l}45,83 \% \\
54,17 \%\end{array}$ \\
\hline $\begin{array}{l}\text { Deportes } \\
\text { No } \\
\text { Sí }\end{array}$ & $\begin{array}{l}217 \\
139\end{array}$ & $\begin{array}{l}60,96 \%{ }^{*} \\
39,04 \%^{*}\end{array}$ & $\begin{array}{r}121 \\
20\end{array}$ & $\begin{array}{l}85,82 \%^{*} \\
14,18 \%\end{array}$ \\
\hline $\begin{array}{l}\text { Economía y negocio } \\
\text { No } \\
\text { Sí }\end{array}$ & $\begin{array}{l}241 \\
115\end{array}$ & $\begin{array}{l}67,70 \%^{*} \\
32,30 \%^{*}\end{array}$ & $\begin{array}{r}121 \\
20\end{array}$ & $\begin{array}{l}85,82 \%^{*} \\
14,18 \%^{*}\end{array}$ \\
\hline $\begin{array}{l}\text { Estilo de vida } \\
\text { No } \\
\text { Sí }\end{array}$ & $\begin{array}{l}226 \\
130\end{array}$ & $\begin{array}{l}63,48 \% \\
36,52 \%\end{array}$ & $\begin{array}{r}102 \\
39\end{array}$ & $\begin{array}{l}72,34 \% \\
27,66 \%\end{array}$ \\
\hline $\begin{array}{l}\text { Judiciales y políticas } \\
\text { No } \\
\text { Sí }\end{array}$ & $\begin{array}{l}224 \\
132\end{array}$ & $\begin{array}{l}62,92 \% \\
37,08 \%\end{array}$ & $\begin{array}{l}94 \\
47\end{array}$ & $\begin{array}{l}66,67 \% \\
33,33 \%\end{array}$ \\
\hline $\begin{array}{l}\text { Sociedad y derechos humanos } \\
\text { No } \\
\text { Sí }\end{array}$ & $\begin{array}{l}206 \\
150\end{array}$ & $\begin{array}{l}57,87 \% \\
42,13 \%\end{array}$ & $\begin{array}{l}68 \\
73\end{array}$ & $\begin{array}{l}48,23 \% \\
51,77 \%\end{array}$ \\
\hline
\end{tabular}

${ }^{*}$ p-level $<0,05$.

FUENTE: SembraMedia. Elaboración propia. 
Tabla 5. Tipo de contenido de estilo de vida de los medios digitales CAL y SAL

\begin{tabular}{|c|c|c|c|c|}
\hline \multirow{3}{*}{$\begin{array}{l} \\
\\
\text { Arquitectura } \\
\text { No } \\
\text { Sí }\end{array}$} & \multicolumn{2}{|c|}{ Organización CAL } & \multicolumn{2}{|c|}{ Organización SAL } \\
\hline & Frecuen & $\%$ & Frecuencia & $\%$ \\
\hline & $\begin{array}{r}121 \\
9\end{array}$ & $\begin{array}{r}93,08 \% \\
6,92 \%\end{array}$ & $\begin{array}{r}35 \\
4\end{array}$ & $\begin{array}{l}89,74 \% \\
10,26 \%\end{array}$ \\
\hline $\begin{array}{l}\text { Diseño gráfico } \\
\text { No } \\
\text { Sí }\end{array}$ & $\begin{array}{r}128 \\
2\end{array}$ & $\begin{array}{r}98,46 \% \\
1,54 \%\end{array}$ & $\begin{array}{r}38 \\
1\end{array}$ & $\begin{array}{r}97,44 \% \\
2,56 \%\end{array}$ \\
\hline $\begin{array}{l}\text { Eventos } \\
\text { No } \\
\text { Sí }\end{array}$ & $\begin{array}{l}91 \\
39\end{array}$ & $\begin{array}{l}70,00 \%{ }^{*} \\
30,00 \% \text { * }\end{array}$ & $\begin{array}{l}17 \\
22\end{array}$ & $\begin{array}{l}43,59 \%{ }^{*} \\
56,41 \%{ }^{*}\end{array}$ \\
\hline $\begin{array}{l}\text { Gastronomía } \\
\text { No } \\
\text { Sí }\end{array}$ & $\begin{array}{l}94 \\
36\end{array}$ & $\begin{array}{l}72,31 \% \\
27,69 \%\end{array}$ & $\begin{array}{r}31 \\
8\end{array}$ & $\begin{array}{l}79,49 \% \\
20,51 \%\end{array}$ \\
\hline $\begin{array}{l}\text { Jardinería } \\
\text { No } \\
\text { Sí }\end{array}$ & $\begin{array}{r}128 \\
2\end{array}$ & $\begin{array}{r}98,46 \% \\
1,54 \%\end{array}$ & $\begin{array}{r}39 \\
0\end{array}$ & $\begin{array}{r}100,00 \% \\
0,00 \%\end{array}$ \\
\hline $\begin{array}{l}\text { Moda } \\
\text { No } \\
\text { Sí }\end{array}$ & $\begin{array}{r}101 \\
29\end{array}$ & $\begin{array}{l}77,69 \% \\
22,31 \%\end{array}$ & $\begin{array}{r}32 \\
7\end{array}$ & $\begin{array}{l}82,05 \% \\
17,95 \%\end{array}$ \\
\hline $\begin{array}{l}\text { Vehículos } \\
\text { No } \\
\text { Sí }\end{array}$ & $\begin{array}{r}122 \\
8\end{array}$ & $\begin{array}{r}93,85 \% \\
6,15 \%\end{array}$ & $\begin{array}{r}39 \\
0\end{array}$ & $\begin{array}{r}100,00 \% \\
0,00 \%\end{array}$ \\
\hline $\begin{array}{l}\text { Viajes } \\
\text { No } \\
\text { Sí }\end{array}$ & $\begin{array}{l}83 \\
47\end{array}$ & $\begin{array}{l}63,85 \% \\
36,15 \%\end{array}$ & $\begin{array}{l}28 \\
11\end{array}$ & $\begin{array}{l}71,79 \% \\
28,21 \%\end{array}$ \\
\hline $\begin{array}{l}\text { Vinos } \\
\text { No } \\
\text { Sí }\end{array}$ & $\begin{array}{r}129 \\
1\end{array}$ & $\begin{array}{r}99,23 \% \\
0,77 \%\end{array}$ & $\begin{array}{r}38 \\
1\end{array}$ & $\begin{array}{r}97,44 \% \\
2,56 \%\end{array}$ \\
\hline $\begin{array}{l}\text { Estilo de vida (sin concretar) } \\
\text { No } \\
\text { Sí }\end{array}$ & $\begin{array}{l}94 \\
36\end{array}$ & $\begin{array}{l}72,31 \%{ }^{*} \\
27,69 \%\end{array}$ & $\begin{array}{r}35 \\
4\end{array}$ & $\begin{array}{l}89,74 \% \text { * } \\
10,26 \%{ }^{*}\end{array}$ \\
\hline
\end{tabular}

${ }^{*} \mathrm{p}$-level<0,05.

FUENTE: SembraMedia. Elaboración propia. 
Dentro de la temática «judiciales y policiales» se observó que el $59,57 \%$ de las empresas SAL trataron la corrupción mientras que esto solo lo hizo el $36,36 \%$ de las CAL, siendo esta diferencia significativa (Tabla 6).

\section{Tabla 6. Tipos de contenido judiciales y policiales de los medios digitales CAL y SAL}

\begin{tabular}{|l|c|c|c|c|}
\hline \multicolumn{2}{|c|}{$\begin{array}{c}\text { Organización CAL } \\
\text { Frecuencia }\end{array}$} & \multicolumn{2}{c|}{$\begin{array}{c}\text { Organización SAL } \\
\text { Frecuencia }\end{array}$} \\
\hline Corrupción & & & & \\
No & 84 & $63,64 \%^{*}$ & 19 & $40,43 \%^{*}$ \\
Sí & 48 & $36,36 \%^{*}$ & 28 & $59,57 \%^{*}$ \\
\hline Judicial & & & & \\
No & 79 & $59,85 \%$ & 29 & $61,70 \%$ \\
Sí & 53 & $40,15 \%$ & 18 & $38,30 \%$ \\
\hline Narcotráfico & & & & \\
No & 108 & $81,82 \%$ & 34 & $72,34 \%$ \\
Sí & 24 & $18,18 \%$ & 13 & $27,66 \%$ \\
\hline Judiciales y policiales (sin concretar) & 30 & $22,73 \%^{*}$ & 19 & $40,43 \%{ }^{*}$ \\
No & 102 & $77,27 \%^{*}$ & 28 & $59,57 \%{ }^{*}$ \\
Sí & & & & \\
\hline
\end{tabular}

${ }^{*}$-level $<0,05$

FUENTE: SembraMedia. Elaboración propia.

En cuanto a la temática dedicada a la "sociedad y derechos humanos" se hallan diferencias significativas. De tal modo que, las organizaciones SAL evidencian un porcentaje significativamente superior en temas relacionados con la desigualdad: «género», «LGTB»y «Pueblos Indígenas» (Tabla 7). 
Tabla 7. Tipo de contenido sociedad y derechos humanos de los medios digitales CAL y SAL

\begin{tabular}{|c|c|c|c|c|}
\hline & & CAL & & SAL \\
\hline & Frecuen & $\%$ & Frecuer & $\%$ \\
\hline $\begin{array}{l}\text { Género } \\
\text { No } \\
\text { Sí }\end{array}$ & $\begin{array}{r}137 \\
13\end{array}$ & $\begin{array}{r}91,33 \%{ }^{*} \\
8,67 \%{ }^{*}\end{array}$ & $\begin{array}{l}57 \\
16\end{array}$ & $\begin{array}{l}78,08 \%{ }^{*} \\
21,92 \%{ }^{*}\end{array}$ \\
\hline $\begin{array}{l}\text { LGTB } \\
\text { No } \\
\text { Sí }\end{array}$ & $\begin{array}{r}140 \\
10\end{array}$ & $\begin{array}{r}93,33 \%{ }^{*} \\
6,67 \% \%^{*}\end{array}$ & $\begin{array}{l}61 \\
12\end{array}$ & $\begin{array}{l}83,56 \%{ }^{*} \\
16,44 \%{ }^{*}\end{array}$ \\
\hline $\begin{array}{l}\text { Pueblos Indígenas } \\
\text { No } \\
\text { Sí }\end{array}$ & $\begin{array}{r}141 \\
9\end{array}$ & $\begin{array}{r}94,00 \%{ }^{*} \\
6,00 \%{ }^{*}\end{array}$ & $\begin{array}{l}62 \\
11\end{array}$ & $\begin{array}{l}84,93 \% * \\
15,07 \% *\end{array}$ \\
\hline $\begin{array}{l}\text { Refugiados } \\
\text { No } \\
\text { Sí }\end{array}$ & $\begin{array}{r}150 \\
0\end{array}$ & $\begin{array}{r}100,00 \% \\
0,00 \%\end{array}$ & $\begin{array}{r}71 \\
2\end{array}$ & $\begin{array}{r}97,26 \% \\
2,74 \%\end{array}$ \\
\hline $\begin{array}{l}\text { Sociedad y derechos humanos } \\
\text { No } \\
\text { Sí }\end{array}$ & $\begin{array}{r}4 \\
146\end{array}$ & $\begin{array}{r}2,67 \% * \\
97,33 \%{ }^{*}\end{array}$ & $\begin{array}{r}7 \\
66\end{array}$ & $\begin{array}{r}9,59 \% * \\
90,41 \%{ }^{*}\end{array}$ \\
\hline
\end{tabular}

${ }^{*} \mathrm{p}$-level<0,05.

FUENTE: SembraMedia. Elaboración propia.

\subsection{Género periodístico}

En relación al género periodístico empleado por los medios digitales, el más usado fue el de «informativos" (62,35\% CAL y 44,86\% SAL). Por otro lado, se han hallado diferencias significativas con porcentajes más elevado en las organizaciones SAL en los géneros: "crítica", "sátira», "crónica no ficción" y «ensayo» (Tabla 8). 
Tabla 8. Género periodístico de los medios digitales CAL y SAL

\begin{tabular}{|c|c|c|c|c|}
\hline \multirow{3}{*}{$\begin{array}{l} \\
\text { Periodismo de Investigación } \\
\text { No } \\
\text { Sí }\end{array}$} & \multicolumn{2}{|c|}{ Organización CAL } & \multicolumn{2}{|c|}{ Organización SAL } \\
\hline & \multicolumn{2}{|c|}{ Frecuencia } & Frecuencia & $\%$ \\
\hline & $\begin{array}{r}208 \\
47\end{array}$ & $\begin{array}{l}81,57 \% \\
18,43 \%\end{array}$ & $\begin{array}{l}80 \\
27\end{array}$ & $\begin{array}{l}74,77 \% \\
25,23 \%\end{array}$ \\
\hline $\begin{array}{l}\text { Informativos } \\
\text { No } \\
\text { Sí }\end{array}$ & $\begin{array}{r}96 \\
159\end{array}$ & $\begin{array}{l}37,65 \%{ }^{*} \\
62,35 \%{ }^{*}\end{array}$ & $\begin{array}{l}59 \\
48\end{array}$ & $\begin{array}{l}55,14 \%{ }^{*} \\
44,86 \%{ }^{*}\end{array}$ \\
\hline $\begin{array}{l}\text { Entrevista y reportaje } \\
\text { No } \\
\text { Sí }\end{array}$ & $\begin{array}{r}180 \\
75\end{array}$ & $\begin{array}{l}70,59 \% \\
29,41 \%\end{array}$ & $\begin{array}{l}70 \\
37\end{array}$ & $\begin{array}{l}65,42 \% \\
34,58 \%\end{array}$ \\
\hline $\begin{array}{l}\text { Crítica } \\
\text { No } \\
\text { Sí }\end{array}$ & $\begin{array}{r}242 \\
13\end{array}$ & $\begin{array}{r}94,90 \% * \\
5,10 \% *\end{array}$ & $\begin{array}{l}94 \\
13\end{array}$ & $\begin{array}{l}87,85 \%{ }^{*} \\
12,15 \%\end{array}$ \\
\hline $\begin{array}{l}\text { Humor } \\
\text { No } \\
\text { Sí }\end{array}$ & $\begin{array}{r}245 \\
10\end{array}$ & $\begin{array}{r}96,08 \% \\
3,92 \%\end{array}$ & $\begin{array}{r}104 \\
3\end{array}$ & $\begin{array}{r}97,20 \% \\
2,80 \%\end{array}$ \\
\hline $\begin{array}{l}\text { Sátira } \\
\text { No } \\
\text { Sí }\end{array}$ & $\begin{array}{r}242 \\
13\end{array}$ & $\begin{array}{r}94,90 \%{ }^{*} \\
5,10 \%\end{array}$ & $\begin{array}{r}105 \\
2\end{array}$ & $\begin{array}{r}98,13 \%{ }^{*} \\
1,87 \%^{*}\end{array}$ \\
\hline $\begin{array}{l}\text { Crónica no ficción } \\
\text { No } \\
\text { Sí }\end{array}$ & $\begin{array}{r}233 \\
22\end{array}$ & $\begin{array}{r}91,37 \% * \\
8,63 \% \text { * }\end{array}$ & $\begin{array}{l}88 \\
19\end{array}$ & $\begin{array}{l}82,24 \%^{*} \\
17,76 \%^{*}\end{array}$ \\
\hline $\begin{array}{l}\text { Ensayo } \\
\text { No } \\
\text { Sí }\end{array}$ & $\begin{array}{r}248 \\
7\end{array}$ & $\begin{array}{r}97,25 \% * \\
2,75 \% \text { * }\end{array}$ & $\begin{array}{l}95 \\
12\end{array}$ & $\begin{array}{l}88,79 \%{ }^{*} \\
11,21 \%{ }^{*}\end{array}$ \\
\hline
\end{tabular}

${ }^{*}$-level<0,05.

FUENTE: SembraMedia. Elaboración propia.

\subsection{Técnica Empleada}

La técnica empleada más recurrente para elaborar la información que ofrecen los medios recogidos en SembraMedia es "actualidad o noticias de última hora». Al mismo tiempo, son las organizaciones CAL las que optaron más por esta modalidad, ya que evidenciaron porcentaje significativamente más elevado (84,68\%). En cambio, las entidades SAL mostraron un resultado significativamente mayor en "cobertura y periodismo de datos" (Tabla 9). 
Además de las técnicas que se muestran en la Tabla 9, SembraMedia recoge dos más ("colectivas" compuesta por 31 organizaciones y «verificación de datos» con 19), pero debido al reducido número de organizaciones que la utilizan se ha optado por no incluirlas en el análisis.

\section{Tabla 9. Técnica empleada para la obtención de la información de los medios digitales CAL y SAL}

\begin{tabular}{|c|c|c|c|c|}
\hline & & CAL & Orga & SAL \\
\hline & Frecuen & $\%$ & Frecuencia & $\%$ \\
\hline $\begin{array}{l}\text { Actualidad o noticias de última hora } \\
\text { No } \\
\text { Sí }\end{array}$ & $\begin{array}{r}36 \\
199\end{array}$ & $\begin{array}{l}15,32 \%{ }^{*} \\
84,68 \%{ }^{*}\end{array}$ & $\begin{array}{l}34 \\
43\end{array}$ & $\begin{array}{l}44,16 \%{ }^{*} \\
55,84 \%{ }^{*}\end{array}$ \\
\hline $\begin{array}{l}\text { Cobertura } \\
\text { No } \\
\text { Sí }\end{array}$ & $\begin{array}{r}161 \\
74\end{array}$ & $\begin{array}{l}68,51 \%{ }^{*} \\
31,49 \%\end{array}$ & $\begin{array}{l}37 \\
40\end{array}$ & $\begin{array}{l}48,05 \%{ }^{*} \\
51,95 \%{ }^{*}\end{array}$ \\
\hline $\begin{array}{l}\text { Curaduría y agregación } \\
\text { No } \\
\text { Sí }\end{array}$ & $\begin{array}{r}197 \\
38\end{array}$ & $\begin{array}{l}83,83 \% \\
16,17 \%\end{array}$ & $\begin{array}{r}70 \\
7\end{array}$ & $\begin{array}{r}90,91 \% \\
9,09 \%\end{array}$ \\
\hline $\begin{array}{l}\text { Periodismo de datos } \\
\text { No } \\
\text { Sí }\end{array}$ & $\begin{array}{r}222 \\
13\end{array}$ & $\begin{array}{r}94,47 \%{ }^{*} \\
5,53 \%{ }^{*}\end{array}$ & $\begin{array}{l}61 \\
16\end{array}$ & $\begin{array}{l}79,22 \%{ }^{*} \\
20,78 \%{ }^{*}\end{array}$ \\
\hline
\end{tabular}

*p-level<0,05.

FUENTE: SembraMedia. Elaboración propia.

\subsection{Origen del Contenido}

Mayoritariamente, los medios digitales acuden a periodistas profesionales para elaborar el contenido de sus noticas (Tabla 10), aunque son las organizaciones CAL las que recurren a ellos en un porcentaje significativamente superior. No obstante, con un porcentaje mucho más reducido, se observan diferencias significativas a favor de las entidades CAL en el empleo de agencias de noticias nacionales y/o internacionales. En cambio, el 15,83\% de las organizaciones SAL utilizan contenido confeccionado por los fundadores mientras que las CAL solo un $5,36 \%$. 
Tabla 10. Origen del contenido de los medios digitales CAL y SAL

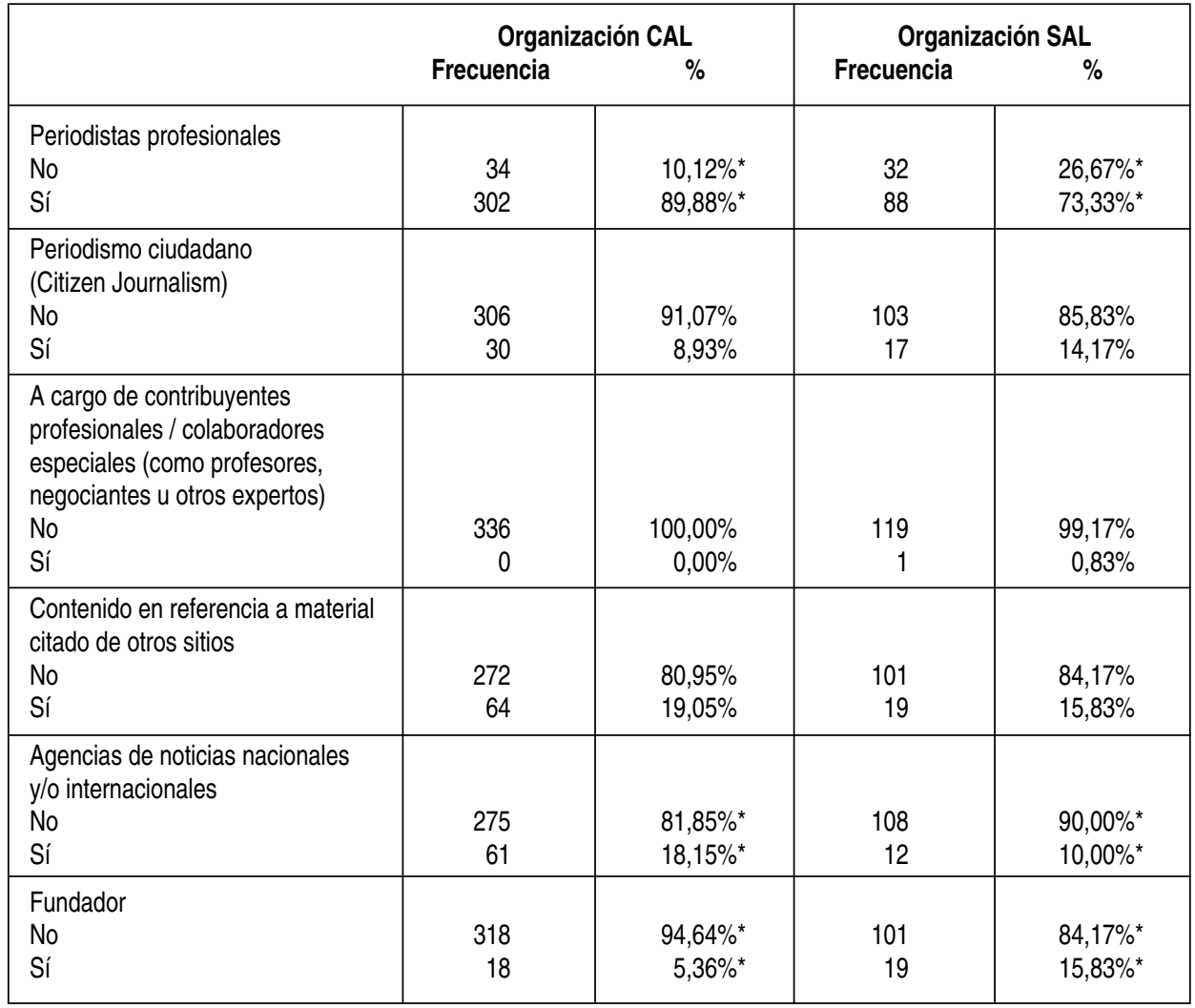

${ }^{*}$ p-level $<0,05$

FUENTE: SembraMedia. Elaboración propia. 


\section{Conclusiones}

Se comprueba que existen importantes diferencias entre los medios digitales con y sin afán de lucro en cuanto a: financiación, temática del contenido y origen del mismo, alcance de sus noticias, plataforma usada para dar soporte, técnica periodística y género utilizado. Los resultados permiten sustentar las siete hipótesis planteadas (Tabla 11), además de contribuir a perfilar las características de las Empresas Sociales Periodísticas (ESP).

\section{Tabla 11. Cuadro de Validación de las hipótesis de la investigación}

\begin{tabular}{|c|c|}
\hline Hipótesis & Derivación \\
\hline $\begin{array}{l}\text { 1. Las empresas SAL ofrecen contenidos de carácter más social y considerados «blan- } \\
\text { dos». }\end{array}$ & Se sostiene \\
\hline $\begin{array}{l}\text { 2. Las empresas SAL ofrecen contenidos orientados a dar voz a los colectivos más des- } \\
\text { favorecidos. }\end{array}$ & Se sostiene \\
\hline 3. Las empresas SAL ofrecen información de reflexión más que la inmediatez. & Se sostiene \\
\hline $\begin{array}{l}\text { 4. La financiación de las empresas SAL no se basa en la comercialización de la informa- } \\
\text { ción. Es decir, deben tener fuentes de financiación ajenas al mercado (donaciones, sub- } \\
\text { venciones, etc.). }\end{array}$ & Se sostiene \\
\hline 5. Las empresas SAL se financian más que las empresas CAL a través del crowdfunding. & Se sostiene \\
\hline 6. En las empresas SAL hay una mayor involucración de los fundadores que en las CAL. & Se sostiene \\
\hline 7. Las empresas SAL se orientan a un periodismo de proximidad, local o nacional. & Se sostiene \\
\hline
\end{tabular}

FUENTE: Elaboración propia. 
El tipo de contenido es un elemento distintivo entre los medios CAL y los SAL, por lo que se confirman la Hipótesis 1 y 2. Se constata que las organizaciones CAL elaboran, en un porcentaje significativamente superior, contenidos vinculados con la tecnología, deportes, economía y negocios (todos temas que entran en la categoría de «noticias duras»), mientras que las organizaciones SAL exhibieron un resultado significativamente más elevado sobre los temas denominados «blandos» y que tradicionalmente son asociados al "público femenino»: medioambiente, eventos, género, LGTB o pueblos indígenas. También se pone de manifiesto una mayor preocupación de las empresas SAL por denunciar la corrupción o las inquietudes sociales. Estas circunstancias repercuten tanto en las técnicas empleadas como en el género periodístico.

Las técnicas más empleadas por las organizaciones CAL son la actualidad y las noticias de última hora, mientras que las SAL cumplen con su función social de contar lo que ocurre en su entorno y muestran diferencias significativas positivas en cobertura y periodismo de datos. Es decir, éstas últimas ofrecen un contenido más reflexivo y de lectura pausada, frente a las primeras que ofrecen información más de inmediatez y de actualidad. En consecuencia, se sustenta la Hipótesis 3.

En relación al género periodístico, los medios digitales emplean de forma habitual el «género informativo" (62,35\% organizaciones CAL y $44,86 \%$ SAL) con un balance positivo y significativo para los CAL. Los medios SAL presentan un resultado significativamente superior en otros géneros periodísticos como: la crítica, crónica no ficción y el ensayo. Dichos géneros son más adecuados para dar respuesta a las temáticas abordadas por estas organizaciones que exigen un periodismo reflexivo y de opinión.

Se constata como las empresas CAL se sustentan fundamentalmente mediante la venta del espacio publicitario. Las SAL, se nutren de otras fuentes de ingresos vinculadas con la involucración de los agentes sociales (donaciones, subvenciones, etc.). Esta diferencia confirma la Hipótesis 4 y 5 , asimismo, se puede suponer que las organizaciones SAL no están tan pendientes de la mercantilización de la información y no dependen tanto de la consecución de audiencias para poder ofrecer una información acorde a su misión y pueden tener una agenda informativa independiente de los intereses comerciales.

Del mismo modo, se observa la implicación directa de las personas fundadoras en las organizaciones SAL, ya que emprenden el negocio y, al mismo tiempo, se involucran en la producción de la noticia. No existe una separación entre la inversión y la producción, lo que permite sustentar la Hipótesis 6. Además, es preciso señalar que las organizaciones SAL nacen con el objetivo de ofrecer un servicio público y tratan de dar cobertura a aquellos hechos que no tienen cabida en las agendas de los medios tradicionales y que, por regla general, no responden a los intereses de mercado como si les ocurre a las CAL.

En este punto, es oportuno detenerse en la presencia del llamado periodismo ciudadano. Era de esperar que existieran diferencias significativas en el uso de esta fuente informativa. Sin embargo, 
aunque la diferencia es considerable (8,93\% para CAL, frente al $14,17 \%$ de las SAL) no llega a ser significativa. Se piensa que es necesario profundizar en este aspecto de forma cualitativa, consideración que se suma a las futuras líneas de investigación.

El origen de la información es principalmente de periodistas profesionales (89,88\% CAL y $73,33 \%$ $\mathrm{SAL})$, aunque son los medios CAL los que recurrieron a éstos en mayor medida, además de a las agencias de noticias nacionales y/o internacionales. Esto puede deberse a que las empresas SAL recurren más a un periodismo participativo y apegado al territorio, que no es cubierto por las agencias de noticias.

Por último, señalar que los medios digitales cubren mayoritariamente noticias nacionales $(78,55 \%$ organizaciones CAL y $73,38 \%$ las SAL). En este aspecto no se hallaron diferencias entre ambos tipos de organizaciones, pero sí en cuanto a la cobertura de temas internacionales donde las empresas CAL mostraron un porcentaje significativamente superior ( $41,75 \%$ CAL y $30,22 \%$ las SAL). Este aspecto está ligado a la Hipótesis 7, "las empresas de carácter social suelen estar más apegadas a los problemas del territorio que cubren informativamente y tratan temáticas de proximidad".

En función de las variables analizadas, se indaga en qué medida los autodenominados medios digitales "SAL" responden a las dimensiones de la Empresa Social de EMES. Se constata como las empresas SAL tienen muchas características propias de las Empresas Sociales conceptualizadas por EMES. Si se atiende a las diferentes dimensiones se puede afirmar que:

- Dimensión Económica Emprendedora: las empresas SAL ofrecen un servicio continuado de información, asumen cierto riesgo económico (garantía de independencia), y cuentan mayoritariamente con profesionales de la información (en el $73,33 \%$ de los casos). Por su propia naturaleza (medios emergentes digitales), se considera que desarrollan una gestión innovadora.

- Dimensión Social: dada la naturaleza de la información disponible en el directorio SembraMedia, es en esta dimensión donde se hallan más elementos diferenciadores. Las empresas SAL ofrecen contenidos, temáticas y géneros que responden mejor a una misión orientada a reducir la asimetría informativa en la sociedad. Ofrecen información reflexiva y crítica, de proximidad y con mayor profundidad que los medios CAL. También dan voz a los colectivos más desfavorecidos. Por último, se observa como los propios fundadores se implican en la generación de la información y, aunque la diferencia no es significativa, es de mención el importante peso del periodismo ciudadano.

- Gobernanza Participativa: para analizar esta dimensión no se dispone de muchas evidencias. Simplemente, se puede constatar una menor dependencia de la inversión publicitaria y, por tanto, de las presiones de las entidades que hacen uso de este recurso. En este sentido, también pueden ofrecer información menos atractiva para el gran público, pero de mayor calidad, al no tener que depender de las audiencias. Respecto al tipo de gobernanza no se dispone de datos. 
En definitiva, las empresas ESP son una realidad emergente que nace con el objetivo de generar un bien común y dar cobertura a aquellos hechos que no tienen cabida en las agendas de los medios tradicionales, y, que, por regla general, no responden a los intereses de mercado. Así, ofrecen contenidos de carácter social, orientados a dar voz a los colectivos más desfavorecidos e información reflexiva. Se orientan a un periodismo de proximidad, local o nacional. Además, parecen tener fuentes de financiación ajenas al mercado (donaciones, subvenciones, etc.) o alternativas como el crowdfunding. También destaca la implicación sólida de las personas fundadoras.

Las futuras líneas de investigación se centrarán en la comprensión de la dimensión gobernanza participativa. En esta línea es importante identificar con nitidez las formas jurídicas que adoptan las empresas. También se quiere profundizar en el papel que desempeña el periodismo participativo en estas organizaciones, como forma de arraigarse al territorio y favorecer la implicación de la ciudadanía. Desde la Unión Europea se insta a "seguir debatiendo el concepto de Empresa Social, como parte de un plan más amplio e integral para apoyar, fomentar y desarrollar la Economía Social, sus principios y su gobernanza" (Monzón y Chaves, 2012:4).

Tal como expone Díaz-Foncea et al. (2012:194), "en el caso de las empresas sociales la intuición y la experiencia parecen mostrar una clara correlación entre su modo de actuar y el retorno social de las inversiones. Pero el paso siguiente es pasar de la apariencia y de la intuición a los datos y la concreción en los análisis y resultados". Es decir, otra línea de investigación sería definir y disponer de criterios e instrumentos para evaluar el cambio temporal e impacto social de las acciones en el sistema de referencia.

Por otra parte, las implicaciones de la investigación inician en la generación de conocimientos a partir del tratamiento de la Empresa Social en una división sectorial precisa, de escaso tratamiento. A nivel teórico, esta investigación se adhiere a anteriores enfoques teóricos, del mismo modo, otorga visibilidad a las ESP. Una aportación importante es que se suministran nuevas evidencias empíricas sobre los tópicos sector de la comunicación y Empresa Social en un ámbito en el que la literatura presenta importantes deficiencias. Además, las implicaciones afectan a dos principales destinatarios: los actores del tejido empresarial periodístico y a la Administración Pública regional. Es conveniente favorecer la cooperación empresarial y realizar un mayor esfuerzo institucional para crear un marco jurídico que mejore el entorno en el que operan las empresas sociales.

En cuanto a las limitaciones de la investigación se identifican dos principales. En primer lugar, sería conveniente contar con más empresas y fuentes de datos enriquecidos que contemplen algunas de las variables que no han podido ser medidas, como, por ejemplo: el impacto social y el sistema de gobernanza. En segundo lugar, y relacionado con lo anterior, hay una limitación empírica derivada de la acotación temporal y el método de captación de datos.

Sin duda, las limitaciones confinan dificultades, desde aumentar el número de variables consideradas y al incremento de los métodos de captación de datos. 


\section{Bibliografía}

AGUADO, T., GIL-JAURENA, I \& MATA-BENITO, P. (2008): "El enfoque intercultural en la formación del profesorado: Dilemas y propuestas", Revista Complutense de Educación, 19(2), 275-292. Disponible en: https://ssrn.com/abstract=2147224.

ARGUDO, J.L. (2011): "Las cooperativas sin ánimo de lucro: ¿vuelta a los orígenes o respuesta a nuevas necesidades sociales?", Gizarte Ekonomiaren Euskal Aldizkaria-Revista Vasca de Economía Social, 3, 179-201.

BARRERA, E. (2007): "La Empresa Social y su responsabilidad social", Innovar, 17(30), 59-76. Disponible en: http://www.scielo.org.co/pdf/inno/v17n30/v17n30a05.pdf.

BONETE-PERALES, E. (1995): Éticas de la información y deontologías del periodismo, Anaya-Spain.

CABRA DE LUNA, M.A. (2017): "Ejemplos de empresas y de emprendimiento social en España", Revista Española del Tercer Sector, 35, 173-180.

CARO-GONZÁLEZ, F.J. (2007): Gestión de Empresas Informativas, Editorial McGraw Hill, España.

CARO-GONZÁLEZ, F.J., GARCÍA-GORDILLO, M.M. \& BEZUNARTEA, O. (2014): "Women and the press: why so few women read newspapers", Estudios sobre el Mensaje Periodístico, 20(2), 9871002. DOI: http://dx.doi.org/10.5209/rev_ESMP.2014.v20.n2.47045.

COMISIÓN EUROPEA (2011): Communication from the commission to the European Parliament, The Council, The European Economic and Social Committee and The Committee of the Regions. Social Business Initiative Creating a favourable climate for social enterprises, key stakeholders in the social economy and innovation. Brussels, 25.10.2011.

CROSS, S. (2017): An investment in trust: Public support grows for nonprofit newsrooms. Recuperado el 6 de julio de 2017, de Knight News Match: https://knightfoundation.org/articles/an-investmentin-trust-public-support-grows-for-nonprofit-newsrooms.

DE MATEO, R., SAURA, L.B. \& CASALS, M.S. (2009): "Gestión de empresas de comunicación", Comunicación Social, 30.

DEFOURNY, J. \& NYSSENS, M. (2012): "El enfoque EMES de la Empresa Social desde una perspectiva comparada", CIRIEC-España, Revista de Economía Pública, Social y Cooperativa, 75, 8-34. Disponible en: https://orbi.uliege.be/bitstream/2268/147129/1/WP1203\%20espagnol.pdf.

DEFOURNY, J. \& NYSSENS, M. (2014): "Social co-operatives: When social enterprises meet the cooperative tradition", Journal of Entrepreneurial and Organizational Diversity, 2(2), 11-33. Disponible en: https://ssrn.com/abstract=2437884. 
DELARBRE, R.T. (2001): "Vivir en la Sociedad de la Información Orden global y dimensiones locales en el universo digital", Revista Iberoamericana Deficiencia, Tecnología, Sociedad e Innovación. Disponible en https://www.oei.es/historico/revistactsi/numero1/trejo.htm.

DÍAZ-FONCEA, M. \& MARCUELLO, C. (2014): "Las empresas sociales en España: concepto y características", Gizarte Ekonomiaren Euskal Aldizkaria-Revista Vasca de Economía Social, 8, 143164.

DÍAZ-FONCEA, M., MARCUELLO, C. \& MARCUELLO, C. (2012): "Empresas sociales y evaluación del impacto social", CIRIEC-España, Revista de Economía Pública, Social y Cooperativa, 75, 179198. Disponible en: https://www.redalyc.org/html/174/17425798010/.

ENCISO, M., GÓMEZ, L. \& MUGARRA, A. (2012): "La iniciativa comunitaria en favor del emprendimiento social y su vinculación con la Economía Social: una aproximación a su delimitación conceptual", CIRIEC-España, Revista de Economía Pública, Social y Cooperativa, 75, 55-80. Disponible en: http://www.redalyc.org/articulo.oa?id=17425798004.

FERRUCCI, P. (2015): "Public journalism no more: The digitally native news nonprofit and public service journalism", Journalism, 16(7), 904-919. DOI: http://dx.doi.org/10.1177/1464884914549123.

GALÁN, J. (2017): "La nueva configuración”. En J. Galán Gamero, G. Aguado Guadalupe, F. CaroGonzález \& J. Manfredi Sánchez, Empresa informativa XXI. Planificación estratégica. Madrid: Síntesis.

JARVIS, J. (2015): El fin de los medios de comunicación de masas. Cómo serán las noticias del futuro, Ed. Gestión 2000.

KAPUSCINSKI, R. (2007): Encuentro con el otro, Anagrama.

KNIGHT, J. (2015): "Internationalization brings important benefits as well as risks", International Higher Education, 46.

KONIECZNA, M. (2014): "Do old norms have a place in new media? A case study of the nonprofit MinnPost", Journalism Practice, 8(1), 49-64. DOl: https://doi.org/10.1080/17512786.2013.793511.

KONIECZNA, M. \& ROBINSON, S. (2014): "Emerging news non-profits: A case study for rebuilding community trust?", Journalism, 15(8), 968-986. DOl: https://doi.org/10.1177/1464884913505997.

LARRAÑAGA-RUBIO, J. (2010): "Industria de los periódicos: nuevos modelos económicos y nuevos soportes", Estudios sobre el mensaje periodístico, 16, 59-78. Disponible en: http://revistas.ucm.es/index.php/ESMP/article/viewFile/esmp1010110059a/11349.

LAVILLE, J.L. (2015): Asociarse para el bien común: Tercer Sector, Economía Social y Economía Solidaria, Icaria. 
MELIÁN, A., CAMPOS, V. \& SANCHIS, J.R. (2011):" Emprendimiento social y empresas de inserción en España. Aplicación del método Delphi para la determinación del perfil del emprendedor y las empresas sociales creadas por emprendedores", REVESCO, Revista de Estudios Cooperativos, 106, 150-172. DOI: https://doi.org/10.5209/rev_REVE.2011.v106.37377.

MITCHELL, A., JURKOWITZ, M., HOLCOMB, J., ENDA, J. \& ANDERSON, M. (2013): "Nonprofit journalism: A growing but fragile part of the US news system", Pew Research Center's Project for Excellence in Journalism. Retrieved August, 1, 2013.

MONZÓN, J.L. (2003): "El cooperativismo en la historia de la literatura económica", CIRIEC-España, Revista de Economía Pública, Social y Cooperativa, 44, 9-32.

Disponible en: https://www.redalyc.org/html/174/17404401/.

MONZÓN, J.L. \& HERRERO-MONTAGUD, M. (2016): "Identificación y análisis de las características identitarias de la Empresa Social europea: aplicación a la realidad de los Centros Especiales de Empleo de la economía española", CIRIEC-España, Revista de Economía Pública, Social y Cooperativa, 87, 295-326. DOI: https://doi.org/10.7203/CIRIEC-E.87.8800.

MONZÓN, J.L. \& CHAVES, R. (2017): Evolución reciente de la Economía Social en la Unión Europea, Comité Económico y Social Europeo, - CIRIEC-International, CES/CSS/12/2016/23406.

Disponible en https://www.eesc.europa.eu/sites/default/files/files/qe-04-17-875-es-n.pdf.

NAVARRO, V., LÓPEZ, J.T. \& ESPINOSA, A.G. (2011): Hay alternativas. Propuestas para crear empleo y bienestar social en España.

NIETO, A. \& IGLESIAS, F. (1993): Empresa informativa, Barcelona: Ariel.

NIETO, A. \& IGLESIAS, F. (2000): Empresa informativa, Barcelona, Ariel.

NOGALES, R. (2017): "La Empresa Social en Europa y España: evolución, relevancia y desafíos", Revista Tercer Sector, 117-140.

OSTROM, E. (1990): Governing the Commons. The Evolution of Institutions for Collective Action, Cambridge: Cambridge University Press.

PALACIOS, L. (2015): Informe Anual de la profesión periodística, 2015, Madrid, APM. Disponible en: https://www.apmadrid.es/wp-content/uploads/2016/11/NFORME-PROFESION-APM-2015_baja_7M.pdf

PÉREZ DE MENDIGUREN, J.C., ETXEZARRETA, E. \& GURIDI, L. (2009): "Economía Social, Empresa Social y Economía Solidaria: diferentes conceptos para un mismo debate", Papeles de Economía Solidaria, 1, 1-41. 
PÉREZ-SUÁREZ, M., ESPASANDÍN-BUSTELO, F. \& SÁNCHEZ-TORNÉ, I. (2017): "Estructura organizativa e innovación en la Economía Social de Andalucía", CIRIEC-España, Revista de Economía Pública, Social y Cooperativa, 90, 35-74. DOI: https://doi.org/10.7203/CIRIEC-E.90.8907.

POBLACIÓN, J.I. \& GARCÍA-ALONSO, P. (1997): Organización y gestión de la empresa informativa, $\mathrm{CIE}$ de Inversiones Editoriales.

POYATO, L. (2017): "El emprendimiento social y su implicación en el Tercer Sector", Revista Española del Tercer Sector, 35, 73-87.

SALINAS, F. \& RUBIO, M.J. (2001): "Tendencias en la evolución de las organizaciones no lucrativas hacia la Empresa Social", CIRIEC-España, Revista de Economía Pública, Social y Cooperativa, 37, 79-116. Disponible en: https://www.redalyc.org/html/174/17403705/.

SIAPERA, E. \& PAPADOPOULOU, L. (2016): "Entrepreneurialism or Cooperativism? An exploration of cooperative journalistic enterprises", Journalism Practice, 10(2), 178-195.

DOI: https://doi.org/10.1080/17512786.2015.1125760.

SOLÓRZANO-GARCÍA, M., GUZMÁN-ALFONSO, C., SAVALL-MORERA, T. \& VILLAJOS-GIRONA, E. (2018): "La identidad de la Empresa Social en España: análisis desde cuatro realidades socioeconómicas", CIRIEC-España, Revista de Economía Pública, Social y Cooperativa, 92, 155-182. DOI: https://doi.org/10.7203/CIRIEC-E.92.9236.

SQUIRES, G.D. (1994): Capital and communities in black and white: the intersections of race, class, and uneven development, State Univ. of New York Pr. 